\title{
Effect of Health Education on the Knowledge, Attitude, and Practice of Fast Food Consumption among Primary Students in Tehran
}

\section{A R T I C L E I N F O}

\section{Article Type}

Original Research

\section{Authors}

Shabanian Kh. ${ }^{1} M S C$, Ghofranipour F. ${ }^{1} P h D$, Shahbazi H. ${ }^{1} P h D$, Tavousi M.* $P h D$
A B S T R A C T

Aims One of the influential factors in maintaining health is nutritional status. As a meal that is prepared quickly and easily and sold in restaurants and eateries, fast food has been popular in many communities. The aim of this study was to assess the effect of health education on the knowledge, attitude, and practice of fast food consumption among primary students in Tehran. Materials \& Methods In this semi-experimental study, 120 primary school students were selected by simple random sampling method during 2015-2016 academic year in Tehran and they were randomly allocated to intervention and control groups. The data were collected from schools in district 6 , Tehran, using a valid and reliable questionnaire before and after the intervention in the areas of knowledge, attitude, practice, and demographic variables. The data were analyzed by SPSS 22 software, using descriptive statistics and independent \& paired t-tests, Chi-square, and Mann-Whitney tests.

Findings Regarding the knowledge, attitude, and practice scores, there were no significant differences between the two groups (intervention and control) before the intervention, but during " 3 months after education", a significant difference in knowledge, attitude, and practice scores was seen $(p<0.01)$. In the intervention group, the mean score for knowledge, attitude, and practice, 3 months after intervention was increased by $7.13,12.96$ and 0.87 scores, respectively $(\mathrm{p}<0.001)$.

Conclusion Increasing the awareness of educational health in terms of knowledge, attitude, and practice is effectivein the reduction of fast food consumption in primary students.

Keywords Knowledge; Attitude; Practice; Fast Foods; Students

\section{CIT A T I O N L IN K S}

[1] Assessment of fast food concumption ... [2] Determinants of fast food consumption among Iranian high school students based ... [3] Effects of fast food consumption on energy intake and diet quality among children in a national ... [4] Fast food consumption among US adults and children: Dietary and ... [5] The influence of market deregulation on fast food consumption and body mass index ... [6] Studing the extent of students' tendency towards fast foods and effective ... [7] Trends of fast food consumption among adolescent and young ... [8] Role of food prepared away from home in the American ... [9] Differences exist in the eating habits of ... [10] Fast food restaurant use among women in the ... [11] Caloric intake from fast food among children and adolescents ... [12] Fast food habits, weight gain, and insulin ... [13] The link between fast food and the obesity ... [14] A survey on some nutritional behavior of obese ... [15] Fast food consumption and educational test ... [16] Fast food restaurant use among adolescents: Associations with nutrient ... [17] Physical activity levels of Canadian children and ... [18] Physical activity and cardiovascular disease risk factor ... [19] Differential associations of fast food and ... [20] Prevention of childhood obesity ... [21] Fast food consumption behaviors in high-school ... [22] Prevalence of overweight, obesity and underweight among high school ... [23] Fathi Azar E. The effect of nutrition education on the knowledge ... [24] Fast food consumption and breakfast skipping: Predictors of weight ... [25] Promoting the purchase of low-calorie foods from school vending ... [26] Effect of promotional training program to reduce the consumption ... [27] Effectiveness of nutrition education on fast food choices ... [28] Assessing knowledge and attitudes toward fast foods among students of ... [29] Comparison of nutrition knowledge, dietary attitude and dietary habit in elementary ... [30] Assessing the effect of education on knowledge, attitude... [31] Health education effects on nutritional ... [32] An examination of family nutrition programs ... [33] Effects of a schoolbased nutrition program diffused throughout ... [34] Do the dietary habits of our ... [35] Emerging theories into the social determinants ... [36] WHO information series on school ... [37] Serum lipid levels in an Iranian ... [38] Health education interventions on student ...

\section{Article History}

Received: April 13, 2017

Accepted: December 4, 2017

ePublished: April 30, 2018

Address: No. 118, Between Tous Street \& Felestin Street, Valiasr ran, Iran

Phone. +98 (21) 66480804

Fax: +98 (21) 66480805 


\section{Introduction}

Undoubtedly, one of the influential factors in maintaining health is nutritional status. Today, people's lifestyle has changed with advances in science, industry, and technology and we see the fading of traditions and indigenous cultures, including nutrition, manners, eating habits, and consumption of prepared foods or fast foods has been popular in many communities $[1,2]$,

Fast foods are the favorite food among young people so that one-third of teens use them outside the home daily [3, 4]. Fast foods are prepared quickly and easily and sold in restaurants and eateries for a meal [5]. This type of food is the product of modern industrial society in the West that has penetrated other communities including our country [6],

Initially, fast food became popular in the United States during the 1970s; currently, it has the largest fast food industry in the world [7,8]. Various studies indicated that a significant increase in fast food consumption is due to change in traditional structure of families; also, these foods are hearty and delicious, low cost, simple, and accessible [9t, 10]. About $12.4 \%$ of American children and adolescents aged 2 to 19 years received their daily energy from fast foods between from 2011 and 2012; in individuals aged 2 to 11 years, this amount increased $8.7 \%$ and in individuals aged 12 to 19 years, it increased $16.9 \%{ }^{[11]}$.

Many experts of nutrition and health believe that fast foods are fattening and harmful to health because of having high-calorie and trans-fatty acids; the likelihood of susceptibility of people to obesity and various diseases including diabetes is caused by the excessive use of high-calorie and high-fat foods and an imbalance between energy intake/expenditure [1,12].

Reports have stated that fast food consumption is common in children and adolescents, and adolescents usually go to fast food restaurants twice a week [13]. In a study conducted by Faqih and Anousheh, it was found that $20 \%$ of adolescents and $10 \%$ of adults consumed fast foods 3 times a week or more [14]. Studies conducted in the US represent the relationship between intake of fast foods with amount of learning in children ${ }^{[15]}$ and it is reported that most teenagers use high-fat diets and low-fruits and vegetables [16].

Today, consumption of fast foods can cause obesity, cardiovascular diseases, diabetes, and osteoporosis due to the mechanization of life and lack of enough movement $[17,18]$. Too much salt in these foods increases the risk of heart attacks and strokes [19]. In addition, consumption of other harmful and high-calorie food detonators such as soft drinks and sauces with fast foods doubles the complications of such foods [20]. In fact, children are victims of present day lifestyle. As a result of incorrect dietary patterns, they are at the risk of cardiovascular diseases, cancers, and diabetes. Whereas having high-fat intake, they consume low fruits, vegetables, and grains than the recommended levels ${ }^{[8]}$.

Given the importance of nutrition as a key factor in determining the health status and high consumption of fast foods in teenagers, fast food consumption negatively affects dietary behaviors in a way that its consumption is in line with lower scores of nutrition knowledge, dietary attitude, and behavior as well as unhealthy eating among children and adolescent [21]. On the other hand, regarding the great importance of childhood and adolescence to the institutionalization of people's eating habits, there is a necessity to adopt a comprehensive approach for informing and sensitizing students about the harmful effects of a high intake of fast foods.

Educational programs play a key role in reducing fast food consumption in the nutritional behavior of the students. Thus, the aim of this study was to investigate the effect of health education on the knowledge, attitude, and practice of fast food consumption among primary students in Tehran.

\section{Materials and Methods}

This is a quasi-experimental study, which was conducted on sixth-grade girl students of primary school in 2 schools; the students were selected from schools in district 6, Tehran, through simple random sampling in the form of intervention and control groups during 2015-2016 academic year. The sample size was determined based on the Cochran's sample size formula. The prevalence rate was obtained from a study conducted by Tabatabai et al. [22].

Primary school students $(n=120)$ were randomly allocated into intervention group $(n=60)$ and control group $(\mathrm{n}=60)$.

The data were collected through a 4-part questionnaire; the first part of the questionnaire was related to the demographic characteristics such as age, height, weight, physical activity, occupation, and education of parents and families. The second part was related to 8 knowledge questions (with Yes, No options), and the third part was related to the 9 attitude questions such as feeling pleasure after eating fast foods and becoming accustomed due to the frequent consumption and excessive weight gain caused by eating these types of foods measured on a 5-point scale between 1 (strongly disagree) and 5 (strongly agree). The fourth part raised 2 questions related to the evaluation of the frequency of fast food consumption in general and in the last month (practice). Validity and reliability 
of this questionnaire were confirmed in the study by Sharifirad et al. [2].

For data collection, all students were initially assured that the information collected will remain confidential and student participation in research is completely voluntary based on personal satisfaction.

After gathering information from intervention group and control groups, in the first stage, educational intervention was performed in intervention group. Educational intervention including the following components was carried out during 6 sessions and followed for 1 month: direct methods consisting of lectures accompanied by teachers, playing role and face to face education with questions and answers, and indirect methods consisting of using educational materials such as pictures, posters, educational movies, etc. Three months after the end of the educational intervention, the second stage of data collection was carried out.

The data were analyzed by SPSS 22, using descriptive statistics and independent \& paired ttests, Chi-square, and Mann-Whitney tests.

\section{Findings}

A total of $70.0 \%$ of students in the intervention group were 11 years old and $73.3 \%$ of fathers and $71.7 \%$ of mothers had a university education. The differences of demographic variables between the intervention group and the control group was not significant (Table 1).

Table 1) Demographic variables in the intervention group and

\begin{tabular}{|c|c|c|c|c|c|}
\hline \multirow{2}{*}{ Variables } & \multicolumn{2}{|c|}{ intervention } & \multicolumn{2}{|c|}{ Control } & \multirow{2}{*}{$p$ value } \\
\hline & $\mathbf{N}$ & Per & $\mathbf{N}$ & Per & \\
\hline \multicolumn{6}{|l|}{ Age } \\
\hline 10 years old & 4 & 6.7 & 5 & 8.3 & \multirow{3}{*}{0.603} \\
\hline 11 years old & 42 & 70.0 & 43 & 71.7 & \\
\hline 12 years old & 14 & 23.3 & 12 & 20.0 & \\
\hline \multicolumn{6}{|l|}{ BMI } \\
\hline Underweight $(<18.5)$ & 25 & 42.4 & 32 & 53.3 & \multirow{4}{*}{0.423} \\
\hline Normal(18.5 to 24.9$)$ & 32 & 54.2 & 26 & 43.3 & \\
\hline Overweight(25 to 29.9 ) & 2 & 3.4 & 1 & 1.7 & \\
\hline Obese $(>30)$ & 0 & 0 & 1 & 1.7 & \\
\hline \multicolumn{6}{|l|}{ Mother's education } \\
\hline Primary & 1 & 1.7 & 1 & 1.7 & \multirow{4}{*}{0.665} \\
\hline Intermediate & 3 & 5.0 & 1 & 1.7 & \\
\hline Diploma & 13 & 21.6 & 14 & 23.3 & \\
\hline University & 43 & 71.7 & 44 & 73.3 & \\
\hline \multicolumn{6}{|l|}{ Father's education } \\
\hline Primary & 1 & 1.7 & 0 & 0 & \multirow{4}{*}{0.212} \\
\hline Intermediate & 1 & 1.7 & 0 & 0 & \\
\hline Diploma & 14 & 23.3 & 12 & 20.0 & \\
\hline University & 44 & 73.3 & 48 & 80.0 & \\
\hline \multicolumn{6}{|l|}{ Mother's job } \\
\hline housewife & 22 & 36.7 & 19 & 31.7 & \multirow{3}{*}{0.293} \\
\hline Employee & 38 & 63.3 & 38 & 63.3 & \\
\hline Retired & 0 & 0 & 3 & 5 & \\
\hline \multicolumn{6}{|l|}{ Father's job } \\
\hline worker & 1 & 1.7 & 0 & 0 & \multirow{5}{*}{0.219} \\
\hline Employee & 43 & 71.6 & 49 & 81.7 & \\
\hline Free job & 12 & 20.0 & 9 & 15.0 & \\
\hline Retired & 1 & 1.7 & 2 & 3.3 & \\
\hline Other & 3 & 5 & 0 & 0 & \\
\hline
\end{tabular}

Regarding the knowledge, attitude, and practice scores, there were no significant differences between the two groups (intervention and control) before the intervention ( $p>0.05$ ), but during " 3 months after education", a significant difference in knowledge, attitude, and practice scores was seen between two groups $(\mathrm{p}<0.01)$.

In the intervention group, the mean score for knowledge, attitude, and practice, 3 months after intervention was increased by $7.13,12.96$ and 0.87 scores, respectively $(\mathrm{p}<0.001)$. While there was no significant change in the control group $(p>0.05$; Table 2).

Table 2) Comparison of the mean scores of knowledge, attitude, and practice before and three months after education

\begin{tabular}{|c|c|c|c|}
\hline Variables & $\begin{array}{c}\text { Intervention } \\
\text { Mean } \pm \text { SD }\end{array}$ & $\begin{array}{c}\text { Control } \\
\text { Mean } \pm \text { SD }\end{array}$ & p value \\
\hline \multicolumn{4}{|l|}{ Knowledge } \\
\hline Before education & $13.03 \pm 0.23$ & $12.87 \pm 0.25$ & 0.564 \\
\hline $\begin{array}{l}\text { Three months after } \\
\text { education }\end{array}$ & $20.16 \pm 0.22$ & $12.98 \pm 0.20$ & $<0.001$ \\
\hline$P$ value & $<0.001$ & 0.701 & - \\
\hline \multicolumn{4}{|l|}{ Attitude } \\
\hline Before education & $21.48 \pm 0.51$ & $21.96 \pm 0.51$ & 0.588 \\
\hline $\begin{array}{l}\text { Three months after } \\
\text { education }\end{array}$ & $34.44 \pm 0.43$ & $21.01 \pm 0.47$ & $<0.001$ \\
\hline$P$ value & $<0.001$ & 0.235 & - \\
\hline \multicolumn{4}{|l|}{ Practice } \\
\hline Before education & $3.05 \pm 1.27$ & $3.01 \pm 1.11$ & 0.879 \\
\hline $\begin{array}{l}\text { Three months after } \\
\text { education }\end{array}$ & $2.18 \pm 0.13$ & $2.78 \pm 1.14$ & 0.003 \\
\hline$P$ value & $<0.001$ & 0.266 & - \\
\hline
\end{tabular}

\section{Discussion}

In recent years, fast food consumption among adolescents has dramatically increased. Many of the habits and dietary patterns form childhood and adolescence remain until the end of life [23]. Dietary habits may not properly form in adolescence, and inappropriate lifestyle patterns during the transition to adulthood remain stable ${ }^{[6,7]}$ will lead to an increased risk of chronic non-communicable diseases such as obesity, cardiovascular disease cardiovascular, cancer, diabetes, etc. [24, 25].

Adolescent students do not have much knowledge about fast foods and their complications. In a study conducted on the fifth grade elementary school girls in Sanandaj, Fatehi Panah et al. [26] found that students had low nutritional knowledge about the fast foods, and their harms, knowledge; the attitude scores of the students in the intervention group were significantly increased after education, but their mean practice score was not significant. Also, students had a low nutritional knowledge about the fast foods and their harms [26].

Likewise, in a research conducted in 2014 by Allen et al., it was found that students had a low nutritional knowledge about fast foods and complications of these types of foods [27]. In a study carried out by Sanaye et al. in 2015 on 228 medical 
students of Shahid Beheshti University evaluating the knowledge and attitude of students towards fast food consumption, it was found that 21.9 students are in poor or very poor level of knowledge to the fast foods [28].

In a study conducted by Lee et al. in South Korea in the field of unbalanced eating behaviors, students were placed in intervention and control groups. Eighty-four titles for nutrition education in the field of unbalanced eating behaviors were selected for intervention group, which was held as group education once a week during 8 weeks. Education had a significant effect on improving knowledge, attitude, and nutritional behavior and the results indicated that serious approaches to educational programs and more attention in an elementary periods are required due to lack of children's nutritional knowledge [29].

Evaluation of Vakili et al. showed that there was a significant difference in the mean scores of knowledge, attitude, and nutritional practice of students on milk and dairy products after implementing educational intervention that reflect the effectiveness of educational interventions for students [30].

Khalaj and Mohammadi Zaidi conducted a study to evaluate the impact of health education on modifying the knowledge and nutritional behavior in the primary school students in Qazvin. In their study, 89 fifth grade students were placed in the intervention group and 87 patients were placed in the control group. After the implementation of educational programs, which was designed for intervention group in direct (face to face with the questions and answers) and indirect methods (using pamphlets and other educational materials) and according to the initial assessment of needs, the effect of education on students' knowledge and practice was measured; the results showed that the students' knowledge and practice scores increased after education [31].

In 2014, a research was conducted by Allen et al. to determine the effectiveness of nutrition education on the selection of prepared food in a simulated environment with a variety of fast foods in adolescents. After 30 minutes of education, selected foods before and after the intervention were compared together, showing that the educational intervention led to the selection of healthier prepared food among adolescents under the study [27].

A study carried out by Bryant in 2011 showed that nutrition education programs in schools and delivery of education to the families by students create positive effects in much better eating children, taking more and more diverse fruits and vegetables as well as the curiosity of children and asking their parents about healthy nutrition [32].
Prelip et al. performed a study on the impact of nutrition education programs based on schools in the metropolitan on attitudes, beliefs, and behaviors related to eating fruits and vegetables; the influence of teachers on students' attitudes towards the consumption of fruit and vegetables created significant change [33].

In our country, like many developing countries, risk factors as well as infection to noncommunicable diseases are rising and age at the onset has been declining. In addition, children and adolescents in our society have inclined to highcalorie foods that lack adequate nutritional value instead of traditional foods and simple meals [34]. School ages, in which basic training takes place, are the important times of life. At this stage of life, nutrition and health are important in order to highly use of educational opportunities. Children's nutritional unhealthy behaviors, which are very common among them, include eating lots of prepared foods and junk food due to their attractive flavors, their reasonable price, and the possibility of eating in leisure [31].

Given the significant developmental changes in childhood and adolescence, receiving inappropriate food groups at these ages can cause multiple diseases and affect the health and eating habits of adult life of young person [35, 36]. If we think the problems are not always be transmitted from generation to generation, preserving the nutritional health of children and adolescents is essential [37]. Students can play a significant role in the education and transferring it to their community. School-based nutrition education programs have been characterized as effective methods to establish nutritional positive attitudes, modifying eating habits and education on the relationship between nutrition and diseases [38]. Since the new generation of teen has a high tendency to consume these types of foods and fast food consumption among adolescents is on the rise in an upward trend, a study with the aim of education program has been designed, which helps adolescents in this area. Students are the best messengers of health. Lifestyle modifications of parents can also be helped through this way; it can strengthen their sense of responsibility against their health children, and laed their unhealthy behaviors to correct and healthy behaviors. There is no doubt that if children are involved in health education and take an active role, they themselves will reach a better understanding of these concepts. Undoubtedly, one of the most beautiful aspects of public participation in health improvement and modification is the active involvement of children and students.

According to the results of the survey, the following suggestions are provided: 
1. Due to the high consumption of fast foods among teenagers, it would need to more serious and more attention.

2. Dietary habits of individuals and its patterns are formed from early childhood, and having healthy eating behaviors in this period affects the health in later years, so it is suggested that serious planning to be done for informing these patterns and providing nutritional knowledge to children and their parents.

3. Creating the right attitude and beliefs about fast food consumption plays an important role in improving the health of students that this should be in educational priorities of the health sector and the role of media in this context should also be seriously considered.

There were some limitations in this study as following: Student Differences in Learning and need to have a different time opportunity to change behavior, lack of continuity of training to change attitude sufficiently and permanently.

\section{Conclusion}

Increasing the awareness of educational health in terms of knowledge, attitude, and practice is effectivein the reduction of fast food consumption in primary students.

Acknowledgments: The authors would like to thank all the participants, who cooperated with us in this study.

Ethical Permissions: IR.TMU.REC.1394.210

Conflict of Interests: The authors declare that they have no competing interests.

Authors' Contribution: Shabanian Kh. (First author), Introduction author/ Original researcher (35\%); Ghofranipour F. (Second author), Methodologist/ Original researcher/ Discussion author (25\%); Shahbazi H. (Third author), Assistant/ Statistical analyst/ Discussion author (15\%); Tavousi M. (Fourth author), Methodologist/ Original researcher/ Statistical analyst/ Discussion author (25\%).

Funding: This study is a part of the M.Sc thesis in health education and supported originally by grants from the Tarbiat Modares University, Department of Health Education.

\section{References}

1- Fazelpour SH, Baghiani Moghadam MH, Nagharzadeh A, Fallahzadeh H, Shamsi F, Khabiri F. Assessment of fast food concumption among people of Yazd city. Toloo-eBehdasht. 2011;10(2):25-34. [Persian]

2- Sharifirad G, Yarmohammadi P, Azadbakht L, Morowatisharifabad MA, Hassanzadeh A. Determinants of fast food consumption among Iranian high school students based on planned behavior theory. J Obes. 2013;2013:147589.
3- Bowman SA, Gortmaker SL, Ebbeling CB, Pereira MA, Ludwig DS. Effects of fast food consumption on energy intake and diet quality among children in a national household survey. Pediatrics. 2004;113 (1 Pt 1):112-8.

4- Paeratakul S, Ferdinand DP, Champagne CM, Ryan DH, Bray GA. Fast food consumption among US adults and children: Dietary and nutrient intake profile. J Am Diet Assoc. 2003;103(10):1332-8.

5- Vogli RD, Kouvonen A, Gimeno D. The influence of market deregulation on fast food consumption and body mass index: A cross-national time series analysis. Bull World Health Organ. 2014;92(2):99-107A.

6- Kuhi K, Mobarak Bakhshayesh M, Abdi Chaykandi R. Studing the extent of students' tendency towards fast foods and effective factors thereupon. Bioeth J. 2013;3(8):157-85. [Persian]

7- ALFaris NA, Al-Tamimi JZ, Al-Jobair MO, Al-Shwaiyat NM. Trends of fast food consumption among adolescent and young adult Saudi girls living in Riyadh. Food Nutr Res. 2015;59:26488.

8- Guthrie JF, lin BH, Frazao E. Role of food prepared away from home in the American diet, 1977-78 versus 1994-96: Changes and consequences. J Nutr Educ Behav. 2002;34(3):140-50.

9- Driskell JA, Meckna BR, Scales NE. Differences exist in the eating habits of university men and women at fast food restaurants. Nutr Res. 2006;26(10):524-30.

10- French SA, Harnack L, Jeffery RW. Fast food restaurant use among women in the Pound of Prevention study: Dietary, behavioral and demographic correlates. Int J Obes Relat Metab Disord. 2000;24(10):1353-9.

11- Vikraman S, Fryar CD, Ogden CL. Caloric intake from fast food among children and adolescents in the United States, 2011-2012. NCHS Data Brief. 2015;(213):1-8.

12- Pereira MA, Kartashov AI, Ebbeling CB, Van Horn L, Slattery ML, Jacobs DR Jr, et al. Fast food habits, weight gain, and insulin resistance (the CARDIA study): 15-year prospective analysis. Lancet. 2005;365(9453):36-42.

13- Frazier DA. The link between fast food and the obesity epidemic. Health Matrix Clevel. 2007;17(2):291317.

14- Faghih A, Anoshe M. A survey on some nutritional behavior of obese people in Jenah, Hormozgan. Hormozgan Med J. 2008;12(1):53-9. [Persian]

15- Tobin KJ. Fast food consumption and educational test scores in the USA. Child Care Health Dev. 2013;39(1):118-24.

16- French SA, Story M, Neumark-Sztainer D, Fulkerson JA, Hannan P. Fast food restaurant use among adolescents: Associations with nutrient intake, food choices and behavioral and psychosocial variables. Int J Obes Relat Metab Disord. 2001;25(12):1823-33.

17- katzmarzyk PT, Ardern CI. Physical activity levels of Canadian children and youth: Current issues and recommendations. Can J Diabetes. 2004;28(1):67-78.

18- Eisenmann JC. Physical activity and cardiovascular disease risk factor in children and adolescents: An overview. Can J Cardiol. 2004;20(3):295-301.

19- Duffey KJ, Gordon-Larsen P, Jacobs DR Jr, Williams OD, Popkin BM. Differential associations of fast food and restaurant food consumption with 3-y change in body mass index: The coronary artery risk development in young adults study. AM J Clin Nutr. 2007;85(1):201-8. 
20- James J, Kerr D. Prevention of childhood obesity by reducing soft drinks. Int J Obes (Lond). 2005;29(Suppl 2):S54-7.

21- Mirkarimi K, Mansourian M, Kabir MJ, Ozouni-Davaji RB, Eri M, Hosseini SG, et al. Fast food consumption behaviors in high-school students based on the Theory of Planned Behavior (TPB). Int J Pediatr. 2016;4(7):2131-42.

22- Ahmadi S, Shahsavari S, Ahmadi H, Tabatabaei far T. Prevalence of overweight, obesity and underweight among high school students in Sanandaj: 2006-2007. Iran J Endocrinol Metab. 2010;12(2):153-9. [Persian]

23- Pourabdelahi P, Zeraati M, Razaviieh SV, Dastgiri S, Ghaem Maghami SJ, Fathi Azar E. The effect of nutrition education on the knowledge and practice of elementary school children regarding junk food intake. J Zanjan Univ Med Sci Health Serv. 2005;13(51):13-20. [Persian]

24- Niemeier HM, Raynor HA, Lloyd-Richardson EE, Rogers ML, Wing RR. Fast food consumption and breakfast skipping: Predictors of weight gain from adolescence to adulthood in a nationally representative sample. J Adolesc Health. 2006;39(6):842-9.

25- Kocken PL, Eeuwijk J, Van Kesteren NM, Dusseldorp E, Buijs G, Bass-Dafesh Z, et al. Promoting the purchase of low-calorie foods from school vending machines: A cluster-randomized controlled study. J Sch Health. 2012;82(3):115-22.

26- Fatehi Panah S, Salavati A, Shafeai R. Effect of promotional training program to reduce the consumption of fast food Case study: Showing promotional Ads, brochures and Counseling to students in Sama primary school. J Health Syst Res. 2015;11(2):435-43. [Persian]

27- Allen KN, Taylor JS, Kuiper R. Effectiveness of nutrition education on fast food choices in adolescents. J Sch Nurs. 2007;23(6):337-41.

28- Sanaye S, Azar Gashb A, Derisi MM, Zamani A, Keivanfar AR. Assessing knowledge and attitudes toward fast foods among students of Shahid Beheshti University of Medical Sciences in 1394. J Med Counc Iran. 2016;34(1):23-30. [Persian]

29- Lee 0, Chang SO, Park MJ. Comparison of nutrition knowledge, dietary attitude and dietary habit in elementary school children with and without nutrition education. J Korean Soc Food Sci Nutr. 2008;37(11):1427-34. [Korean]

30- Vakili M, Baghiani Moghadam MH, Pirzadeh A, Dehghani M. Assessing the effect of education on knowledge, attitude and practice of guidance school students about milk and dairy products. J Knowl Health. 2008;2(4):40-5. [Persian]

31- Khalaj M, Mohammaddi Zeidi I. Health education effects on nutritional behavior modification in primary school students. J Shahrekord Univ Med Sci. 2006;8(1):41-9. [Persian]

32- Gabrielle La'Dale B. An examination of family nutrition programs implemented by Mississippi State University Extension Service in Jackson Public Schools [Dissertation]. Mississippi: Mississippi State University; 2011.

33- Prelip M, Slusser W, Thai CL, Kinsler J, Erausquin JT. Effects of a school-based nutrition program diffused throughout a large urban community on attitudes, beliefs, and behaviors related to fruit and vegetable consumption. J Sch Health. 2011;81(9):520-9.

34- Kelishadi R, Ardalan G, Gheiratmand R, Sheikholeslam R, Majdzadeh SR, Delavari AR, et al. Do the dietary habits of our community warrant health of children and adolescents now and in future? CASPIAN study. Iran J Pediatr. 2005;15(2):97-109. [Persian] 35- Watt RG. Emerging theories into the social determinants of health: Implications for oral health promotion. Community Dent Oral Epidemiol. 2002;30(4):241-7.

36- Kwan S, Petersen PE. WHO information series on school health [Internet]. Geneva: World Health Organization; 2003 [cited 2017 Jul 15]. Available from: http://www.who.int/oral_health/media/en/orh_school_ doc11.pdf.

37- Azizi F, Rahmani M, Madjid M, Allahverdian S, Ghanbili J, Ghanbarian A, et al. Serum lipid levels in an Iranian population of children and adolescents: Tehran lipid and glucose study. Eur J Epidemiol. 2001;17(3):281-8

38- Dehdari T, Khezeli M, Bakhtiyari M, Nilsaz M. Health education interventions on student nutrition: A systematic review. J Health Hyg. 2012;3(3):62-72. [Persian] 